\title{
SPRINGBACK PREDICTION OF STRETCHING PROCESS USING FINITE ELEMENT ANALYSIS FOR DP600 STEEL SHEET
}

\author{
Jan SLOTA*, Ivan GAJDOS*, Emil SPIŠÁK**, Marek ŠISER* \\ *Department of Computer Support of Technology, Technical University of Košice, Mäsiarska 74, 04001 Košice, Slovakia \\ *Department of Technology and Materials, Technical University of Košice, Mäsiarska 74, 04001 Košice, Slovakia \\ jan.slota@tuke.sk, ivan.gajdos@tuke.sk, emil.spisak@tuke.sk, marek.siser@tuke.sk
}

received 3 December 2015, revised 12 December 2016, accepted 10 December 2016

\begin{abstract}
Springback phenomenon is well predicted for some mild steel materials, but not for steels with higher strength. One of the most used tools to stamping optimization is usage of finite element analysis. In order to accurate describe the real behaviour of the materials for stamping of vehicle panels, the application of proper hardening rule seems to be crucial. Due to higher accuracy of predicted results, high strength steel sheets are usually modelled by means of kinematic or mixed isotropic-kinematic hardening models. In this paper the springback prediction of advanced high strength steel DP600 by numerical simulation was investigated. Through cyclic tension-compression tests, the material characterization has been performed for DP600 steel sheet. Different hardening models (isotropic, kinematic and mixed isotropic-kinematic) used in the simulations were compared with expreriment. The Yoshida-Uemori model succesfully describe the kinematic behaviour of the material and provided more accurate results than others.
\end{abstract}

Key words: Sheet Metal Forming, Springback, Simulation

\section{INTRODUCTION}

Stamping process is the most commonly used manufacturing process to produce thin vehicle panels. The biggest challenge in stamping process is to ensure satisfying design specifications without causing defect as splits, wrinkling, skid lines, surface distortions and springback issues (Slota et al., 2015). The springback phenomenon is still the current issue in automotive industry, considering mainly materials which have higher strength (Slota et al., 2012). Numerical simulation by finite element method (FEM) is widely used as a tool for engineers to improve the part design taking into account the process limitations. Finite element analysis (FEA) is a well-established tool for analyzing and predicting sheet forming strains for various materials and test conditions. FE simulation of springback, however, is much more sensitive to numerical tolerances and to material model than forming simulations. Numerical procedures that must be considered more critical for springback simulation include the spatial integration scheme, element type and time integration scheme (implicit, explicit, onestep). Various material representations affect springback simulations significantly such as the unloading scheme, strain hardening rule, evolution of elastic properties, plastic anisotropy, Bauschinger effect, etc. (Wagoner et al., 2013).

During the forming operations, the sheet metal often undergoes to bending-unbending and stretching processes. For example, when a sheet is drawn over a tool radius or draw bead. In these cases, the material is subjected to complex strain paths which make it difficult to accurately predict the final shape of the part after forming. Because of this, the accuracy of the implemented product is dependent on the accuracy of the implemented material constitutive model amongst others.

Complex material models are presented increasingly in FEM codes to provide accurate predictions of material behaviour. These models take into account different phenomena, such as the Bauschinger Effect, the transient behaviour and the permanent softening. Predictions of all these effects which affect the final shape are connected to the hardening rule. Hardening models describe the evolution of the initial yield surface. It is recommended to use various types of hardening models, according to their ability to explain and exact predict plastic behaviour during the given deformation process (Silvestre, 2015). With the increased complexity of hardening model, it is able to increase the accuracy of the predictions (Eggertsen and Mattiasson, 2010).

There are four types of hardening models which may arise during sheet metal forming processes: isotropic models, kinematic models, rotational and distortional hardening models (Bruschi et al., 2014). Isotropic hardening models are used for simple applications. They are able to express the proportional expansion of the initial yield surface (Slota et al., 2014; Bruschi et al., 2014). The advantage of these models is that are able to predict hardening behaviour of a high range of different materials and they are widely used due to their simplicity. However, FEM simulation of new advanced materials, such as advanced high strength steels (AHSS) or ultra high strength steels (UHSS), need more complex formulation of hardening. The use of isotropic hardening models overestimates the hardening in reversal loading under reverse strain paths. This is due to the occurrence of different phenomena during reversal loading which occur commonly in high strength materials, especially as: the Bauschinger effect, the transient behaviour and the permanent softening (Bruschi et al., 2014). Kinematic hardening laws offer more sophisticated models than isotropic. These models assume, that the yield surfaces preserve their shape and size but translate through the stress space. Due to their ability to predict some phenomena mentioned above, kinematic hardening models have received special attention in the 
last years (Eggertsen and Mattiasson, 2010). The Bauschinger effect is a clear illustration of how the mechanical response of a metallic material depends not only on its current stress state but also on its history of plastic deformation. A combination of the isotropic and a non-linear kinematic hardening rule (also called mixed hardening models) gives a uniform expansion and translation in shape of the yield surface. Mixed hardening models can predict properly material behaviour of AHSS (Lemoine et al., 2011). According to Kim et al. (2012) the hardening behaviour including the transient behaviour and Bauschinger effect was well described by a modified mixed Chaboche model for dual phase steels. Based on the Yoshida combined isotropic-kinematic hardening model, the constitutive parameters for several AHSS, such as DP780 and DP980 was determined by Shi et al. (2008). Yoshida model was able to determine the stress and strain behaviours in various cycle tension and compression tests. The complexity and accuracy of models depend on the number of material parameters and history variables. Every model has its precise requirements in terms of experimental data and testing needed to identify its parameters. However, in the characterization of stamping operations, cyclic loading experimental tests are generally used in order to analyse kinematic hardening (Lemoine et al., 2011). Several authors have proposed several reverse loading tests (Cao et al., 2009; Silvestre et al., 2015; Eggertsen and Mattiasson, 2010; Slota et al., 2014; Yoshida and Uemori, 2002; Boger et al., 2005; Chongthairungruang et al., 2013; Kuwabra et al., 2009; Piao et al., 2012). Rotational hardening model assumes that the yield locus rotates and distortional hardening model assumes that the yield locus distorts. Nevertheless, the capabilities of isotropic and kinematic hardening models to fully describe the hardening curve upon opposite load, it cannot describe the anisotropic and distortional hardening behaviour. It is due to the change of the sheet metal plastic anisotropy at increasing level of deformation as a result of the texture evolution (Bruschi et al., 2014).

Advanced high strength steels represent special challenges because in general they have higher strength and ductility combinations than conventional steels for vehicle panels and they make use of either very coarse microstructures (DP steels) or straininduced transformations and complex hardening behaviour (TRIP and TWIP steels). These differences manifest themselves in large changes of elastic "modulus" following plastic deformation, very large hardening transients following a stress reversal, and high temperatures attained by the plastic work in areas of large deformation. Much of the current research on springback focuses just on these aspects (Wagoner et al., 2013).

The goal of this research is to study springback effects of dual phase steel grade DP600 by both, experimentally and numerically. To verify the predicted results of investigated steel, experimental tests were carried out. FE simulations of the forming with stretching were performed in explicit FE code. Accurate springback prediction requires knowing the stress state through the part before unloading, which is controlled by the plastic response of the material during stamping. Parameters of material model that can often be put aside in satisfactory stamping simulations must be included for springback simulations (Yoshida and Uemori, 2003). Among these features belong: Bauschinger effect, hardening stagnation, permanent softening and early re-yielding in the compression phase of the cycle. These features can be revealed performing cyclic tension-compression test. Not all of new material models describing this features. Yoshida-Uemori kinematic hardening material model (Mahmoudi et al., 2011) describes kinematic hardening of the loading surface, combined isotropic-kinematic hardening for the bounding surface, Bauschinger transient similar to a general two surface model and work hardening stagnation at large plastic strain. First step in process of implementation these features is to perform cyclic test under tension-compression load. Next step is fit the experimental curves by means of optimization technique. Experimental and numerical results concerning springback after stamping were compared.

\section{EXPERIMENTAL PROCEDURE}

\subsection{Experimental material}

The material investigated in this work was the high strength dual phase steel grade DP600 with a thickness of $1.0 \mathrm{~mm}$. Mechanical properties of this steel sheet obtained from uniaxial tensile test are shown in Tab. 1. The data shown in the table represents mean values.

Tab. 1. Mechanical properties of DP600 steel sheet

\begin{tabular}{|c|c|c|c|c|c|}
\hline Material & $\begin{array}{c}\mathbf{R e} \\
{[\mathrm{MPa}]}\end{array}$ & $\begin{array}{c}\mathbf{R m} \\
{[\mathrm{MPa}]}\end{array}$ & $\begin{array}{c}\mathbf{A} 80 \\
{[\%]}\end{array}$ & $\begin{array}{c}\mathbf{K} \\
{[\mathrm{MPa}]}\end{array}$ & $\mathbf{n}[-]$ \\
\hline DP 600 & 383 & 620 & 26.1 & 1008 & 0.179 \\
\hline
\end{tabular}

In order to characterizing the Bauschinger effect during reverse deformation including the transient Bauschinger strain, early re-yielding, work-hardening stagnation and permanent softening behaviour of investigated steel, cyclic tests under tensioncompression load were performed. The cyclic tests were carried out using TiraTest testing machine. Elongation of the specimen (Fig.1) was controlled by crosshead displacement of the testing machine.

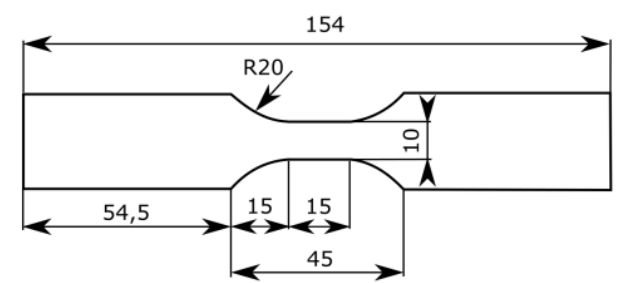

Fig. 1. Dimensions of specimen used for cyclic tension-compression test

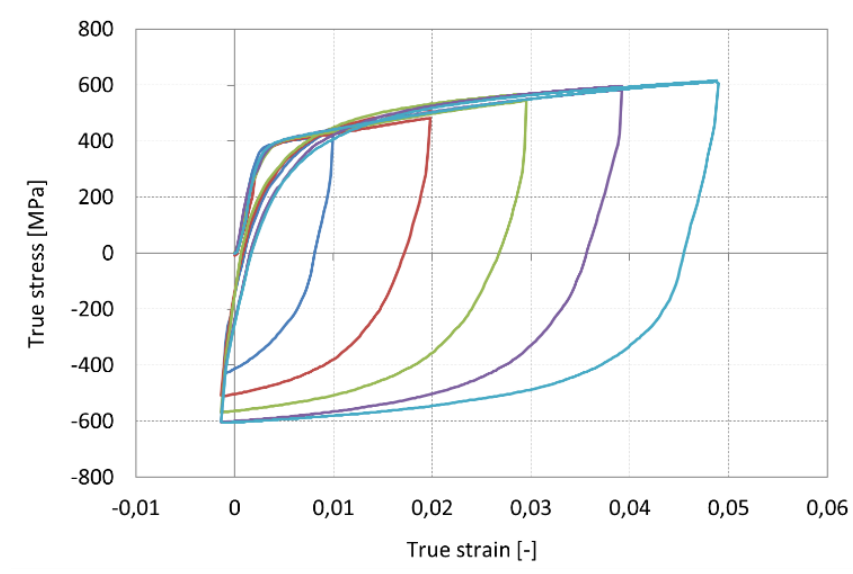

Fig. 2. Tension-compression experimental curve of DP600 
Tension-compression test was started by tension load as first part of full cycle. After a specific crosshead stroke corresponding to a defined pre-strain level, load was reversed to compression until reaching crosshead displacement according to a given compression strain. Next, re-loading in tension direction was introduced until the crosshead stroke being equal to that in the first tension. The pre-strain levels between 1 and 5 percent were studied (Fig. 2). It should be noted that higher pre-strain levels could lead to a buckling of the sample.

\subsection{FEM simulation}

Springback effect of the investigated steel by means of numerical simulation and the final resulted shapes of the sample after tool removal were predicted. Numerical simulation was performed in explicit FE code and the input parameters are presented in Tab. 2.

Tab. 2. Input parameters of FE analysis

\begin{tabular}{|c|c|c|c|}
\hline Parameter & Value & Parameter & Value \\
\hline $\begin{array}{c}\text { Time integra- } \\
\text { tion scheme }\end{array}$ & Explicit & Element type & Shell \\
\hline Mesh type & Rectangle & Refinement & 0 \\
\hline Mesh size & $1.5 \mathrm{~mm}$ & Holding force & $10 \mathrm{kN}$ \\
\hline $\begin{array}{c}\text { Nr. of integra- } \\
\text { tion points }\end{array}$ & 5 & $\begin{array}{c}\text { Friction coeffi- } \\
\text { cient }\end{array}$ & 0.15 \\
\hline
\end{tabular}

The stamping simulation was consisting of two stages. The first stage was the deep-drawing process and the second stage was springback after the tool release process. The FE model with boundary conditions were generated according to experimental setup. The shell elements were used to mesh the sample.

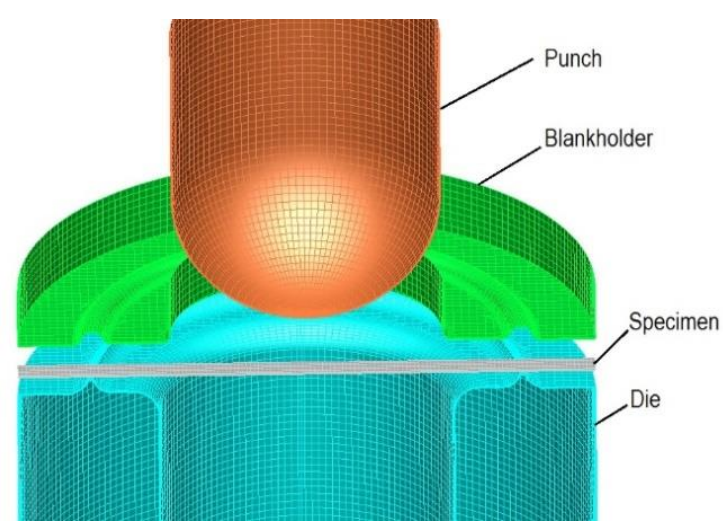

Fig. 3. Experimental setup used in experiment

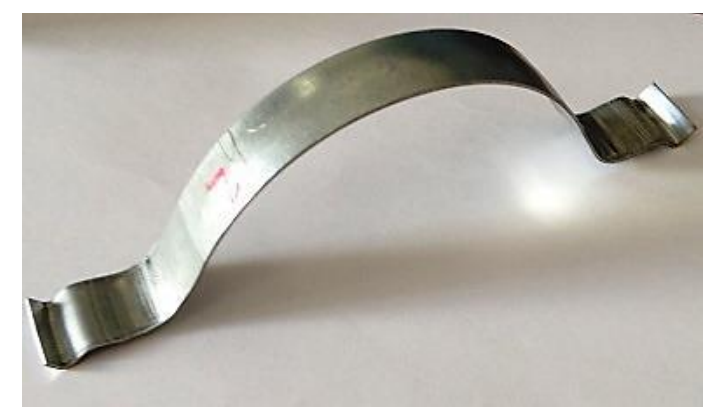

Fig. 4. Formed sample for springback analysis
All parts of the tool were setup as a rigid body. The friction coefficient of 0.15 was set for every contact surface of the tool. The springback profiles of the deformed samples calculated by FE simulations were compared with experimental results.

For this research was selected tool which is used into the Nakajima test. Geometry of the tool is showed in Fig. 3. This experiment was performed on the universal testing machine Erichsen 145-60. Blankholder force was set to the values of $10 \mathrm{kN}$. Experimentally stamped specimen of investigated high strength steel is presented in Fig. 4. The geometry was selected due to existence of drawbeads and great diameter of punch what may have influence to the diminishing problems associated with the problems of numerical modeling.

\subsection{Results}

To compare experiments with numerical material models, both analyses were performed using the same process conditions. When advanced material models which consider kinematic hardening were obtained, numerical simulation of tensile-compression test was performed and the strain paths were plotted. For this purpose, the mixed isotropic-kinematic hardening model of Chaboche and Yoshida-Uemori kinematic hardening model were used. The true stress-strain curves obtained from the numerical tension-compression cyclic tests compared with experiment are presented in Fig. 5. When Yoshida-Uemori kinematic hardening material model was used, it can be observed, that transient Bauschinger effect is described preferably. The stress-strain curve illustrated in Fig. 5 shows, that the material behaviour is described with higher accuracy than isotropic or mixed hardening models.

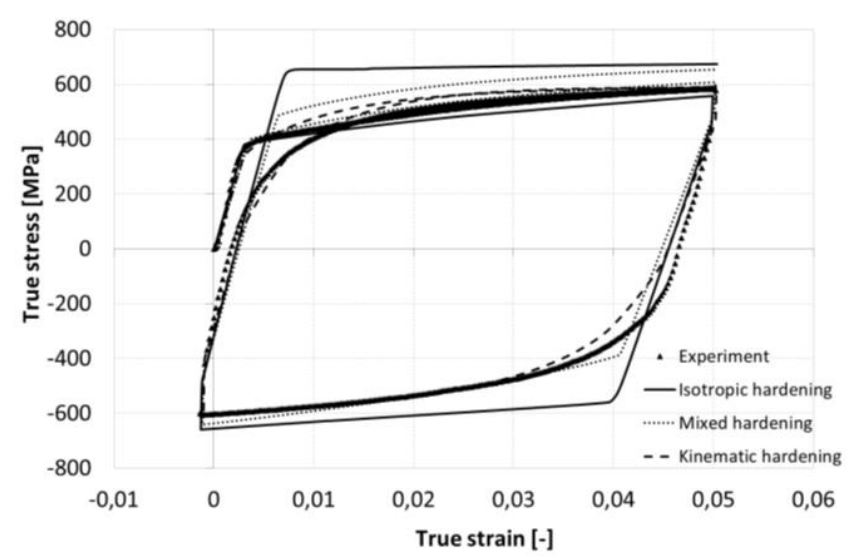

Fig. 5. True stress-strain curves obtained from cyclic $T-C$ test from numerical simulation and the real experiment of DP600 steel sheet

In Fig. 6 is illustrated course of the contact force between punch and the sheet metal. From this graph implies that the drawing stroke was the same in the case of numerical simulation and real experiment. The load-displacement curves were calculated by FE simulations using different materials models and compared with the experimental results. From these three curves implies, that the Yoshida-Uemori kinematic hardening material model predicts experimental course more accurate than others. 


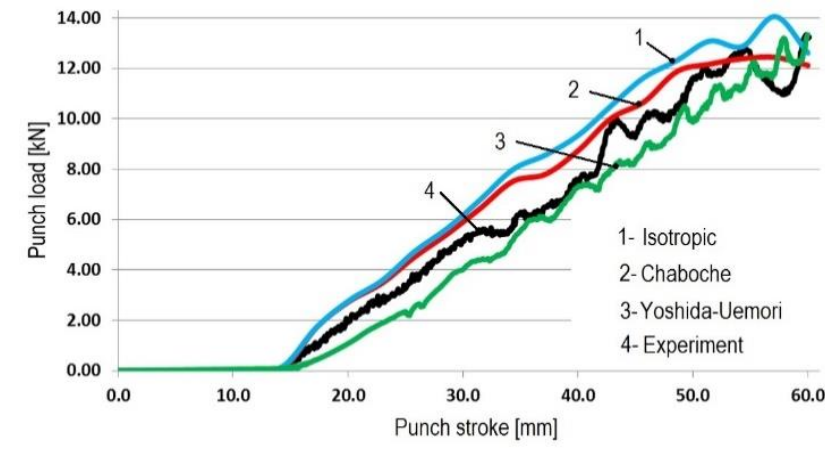

Fig. 6. Experimentally measured punch load curve during stamping in comparison with FE simulation results using different hardening models for the DP600 steel

The final shape of the stamped part after springback obtained from simulation and the real experiment is shown in Fig. 7. It is shown, that the predicted profiles of the part after springback better agreed with measured data of investigated material when the Yoshida-Uemori kinematic hardening material model was used. This result is confirmed by the course of stress-strain curve shown in the Fig. 5. Cross-section profile predictions from Yoshida-Uemori model most fairly agreed with the experimental results, whereas the isotropic provided the least accurate predictions. The springback prediction of high strength steels by FE simulation with using isotropic hardening model seems to be inadequate.

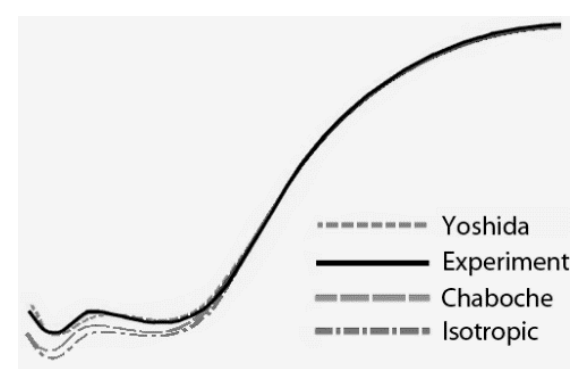

Fig. 7. Cross-section profiles of the sample after springback calculated by FEM using different hardening models in comparison with experimental results for DP600 steel

\section{CONCLUSIONS}

From the research presented in this paper implies, that the hardening models which consider kinematic hardening are more accurate within springback simulation. Implementation of advanced hardening material models presented in this research is associated with the need of an appropriate experimental test to obtain stress-strain curve from cyclic tension - compression test. In compression phase of the cycle, this test is associated with the problem of buckling. Therefore, it is necessary to use a special fixture to prevent buckling. Designed fixture allows reliably measure stress-strain curves. Subsequently, hardening models which describe springback issue with great accuracy can be implemented. Yoshida-Uemori kinematic hardening model was successfully fitted to the experimental stress-strain curves obtained from cyclic test. The numerical prediction of springback with this hardening model agreed well with experimental data. The application of conventional isotropic hardening model for materials such advanced high strength steels is unsatisfactory.

\section{REFERENCES}

1. Boger R.K., Wagoner, R.H., Barlat F., Lee M.G., Chung K. (2005), Continous, large strain, tension/compression testing of sheet material, International Journal of Plasticity, 21, 2319-2343.

2. Bruschi S., Altan T., Banabic D., Bariani P.F., Brosius A., Cao J., Tekkaya A. E. (2014), Testing and modelling of material behaviour and formability in sheet metal forming, CIRP Annals-Manufacturing Technology, 63(2), 727-749.

3. Cao J., Lee W., Cheng H.S., Seniw M., Wang H., Chung K. (2009), Experimental and numerical investigation of combined isotropickinematic hardening behavior of sheet metals, International Journal of Plasticity, 25, 942-972.

4. Chongthairungruang B., Uthaisangsuk V., Suranuntchai S., Jirathearanat S. (2013), Springback prediction in sheet metal forming of high strength steels, Materials \& Design, 50, 253-266.

5. Eggertsen P., Mattiasson K. (2010), On constitutive modeling for springback analysis, International Journal of Mechanical Sciences, 52(6), 804-818.

6. Kim J.H., Kim D., Barlat F., Lee M. (2012) Crystal plasticity approach for predicting the Bauschinger effect in dual-phase steels. Materials Science and Engineering: A, 539, 259-270.

7. Kuwabara T., Kumano Y., Ziegelheim J., Kurosaki I. (2009), Tension-compression asymmetry of phosphor bronze for electronic parts and its effect on bending behavior, International Journal of Plasticity, 25(9), 1759-1776.

8. Lemoine X., Durrenberger L., Zhu H., Kergen R. (2011), Mixed hardening models: parameters identification on AHSS steels, IDDRG Conference Proceedings.

9. Mahmoudi A.H., Pezeshki-Najafabadi, S.M., Badnava, H. (2011), Parameter determination of Chaboche kinematic hardening model using a multi objective Genetic Algorithm, Computational Materials Science, 50, 1114-1122.

10. Piao K., Lee J.K., Kim J.H., Kim H.Y., Chung K., Barlat F., Wagoner R.H. (2012), A sheet tension/compression test for elevated temperature, International Journal of Plasticity, 38, $27-49$.

11. Shi M., Zhu X., Xia C., Stoughton T. (2008) Determination of nonlinear isotropic/kinematic hardening constitutive parameters for AHSS using tension and compression tests, Numisheet Conference, 137-142.

12. Silvestre E., Mendiguren J., Galdos L., Sáenz de Andragona E. (2015), Comparison of the hardening behaviour of different steel families: From mild and stainless steel to advanced high strength steels, International Journal of Mechanical Sciences, 101-102, 10-20.

13. Slota J., Jurčišin M., Spišák E. (2012), Numerical and experimental springback determination of sheet metals in an air bending process, Acta Metallurgica Slovaca, 18(4), 200-209.

14. Slota J., Jurčišin M., Spišák E., Sleziak, T. (2014), An investigation of springback in sheet metal forming of high strength steels, Applied Mechanics and Materials, 693, 370-375.

15. Wagoner R.H., Lim H., Lee M.G. (2013), Advanced issue on springback, International Journal of Plasticity, 45, 3-20.

16. Yoshida, F., Uemori, T. (2002), A model of large-strain cyclic plasticity describing the Bauschinger effect and workhardening stagnation, International Journal of Plasticity, 18, 661-686.

17. Yoshida, F., Uemori, T. (2003), A model of large-strain cyclic plasticity and its application to springback simulation, International Journal of Mechanical Sciences, 45(10), 1687-1702.

The work has been accomplished under the research project No. APVV0273-12: "Supporting innovations of autobody components from the steel sheet blanks oriented to the safety, the ecology and the car weight reduction" financed by the Slovak Research and Development Agency and VEGA 1/0872/14 supported by the Scientific Research Committee". 